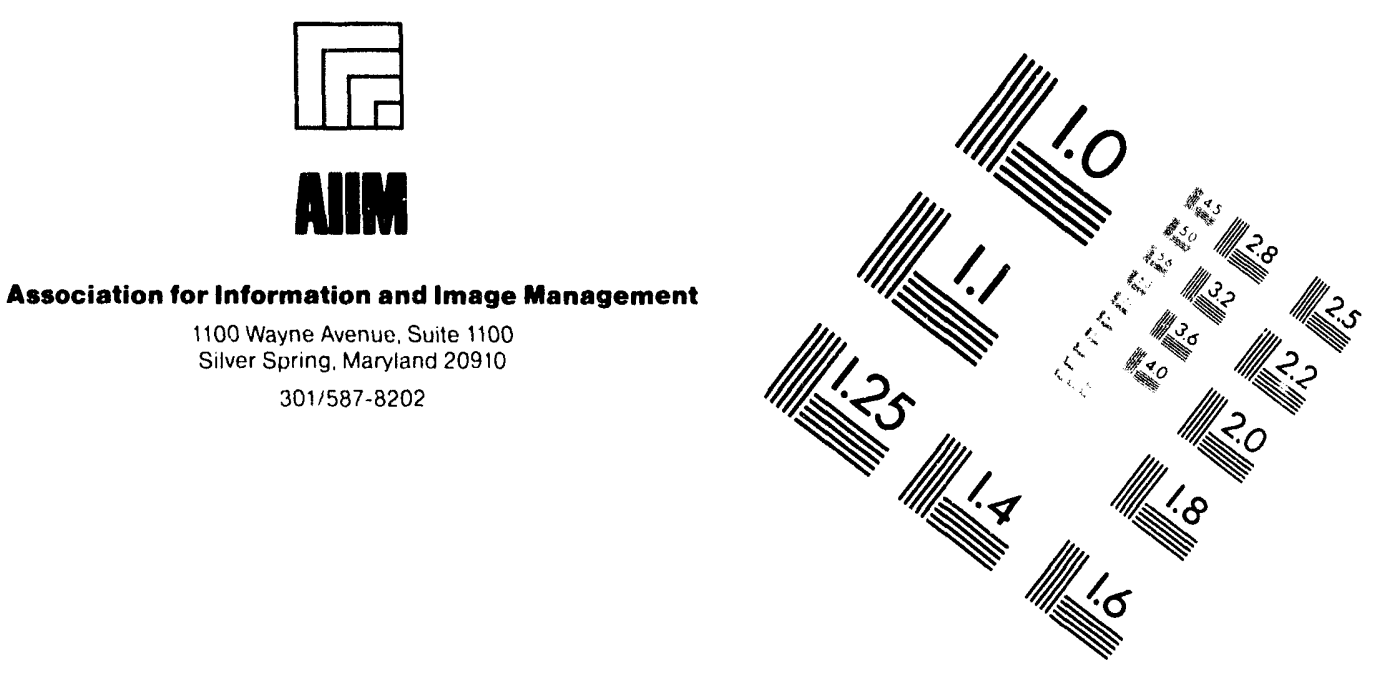

\title{
Centimeter
}

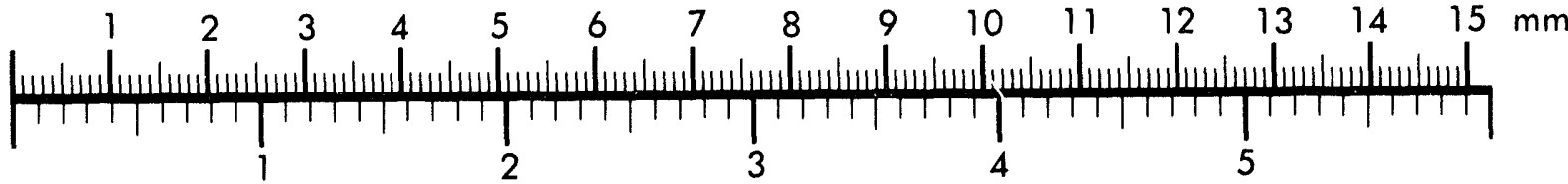

Inches
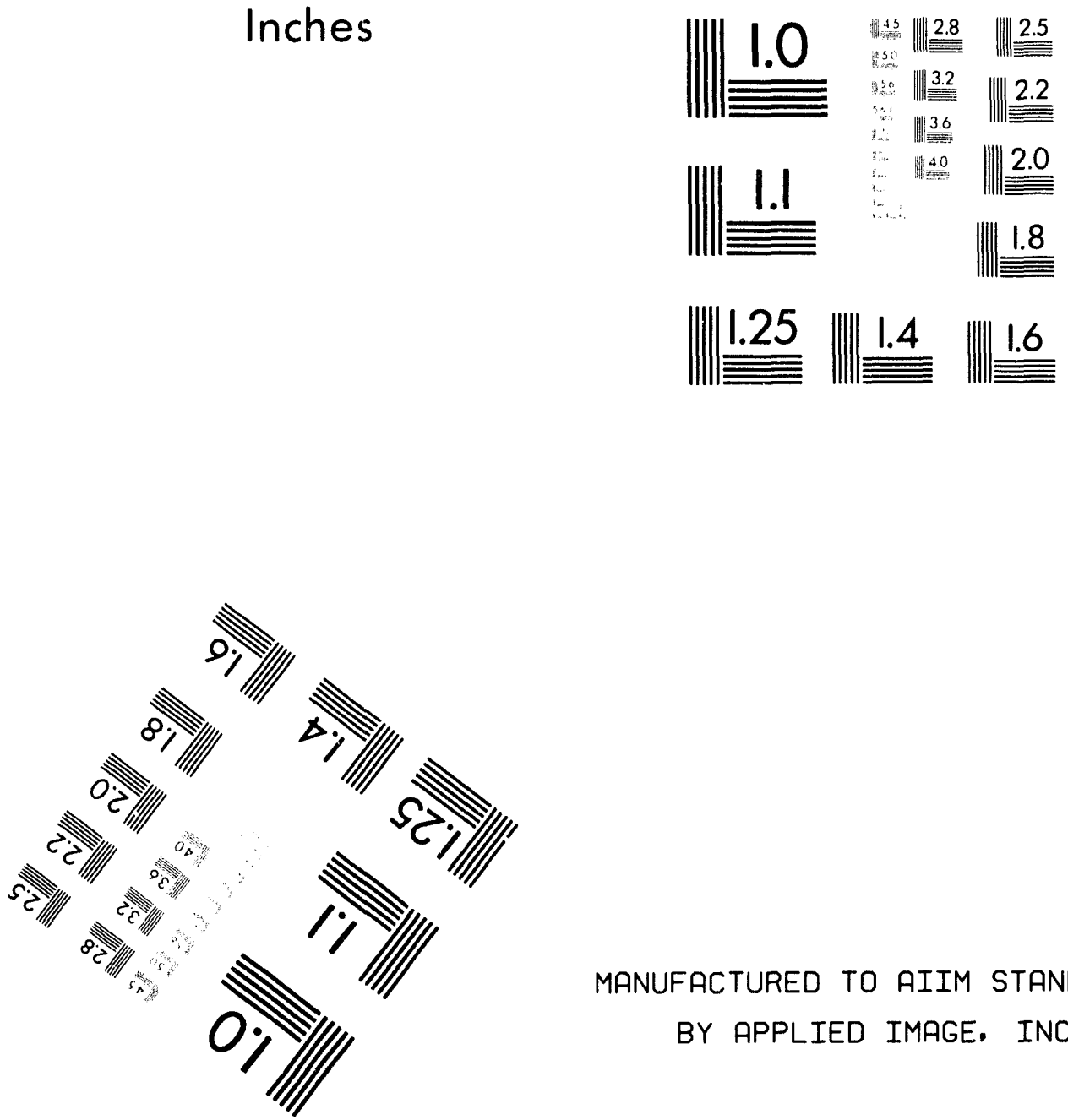

MANUFACTURED TO AIIM STANDARDS

BY APPLIED IMAGE. INC.

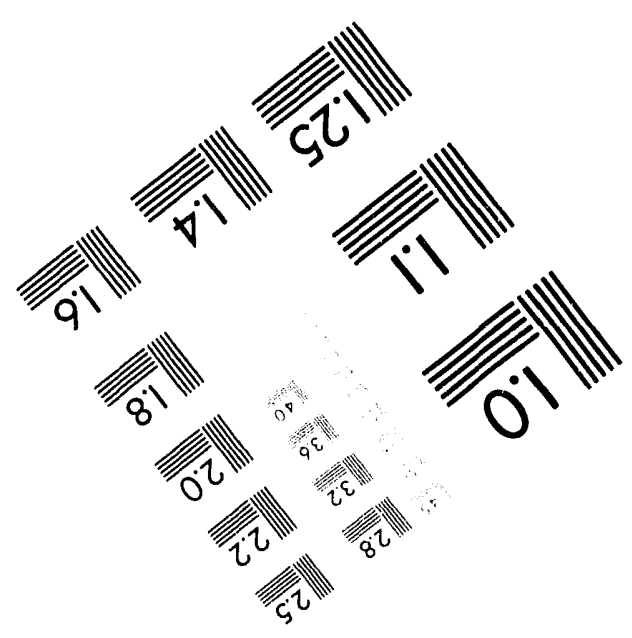



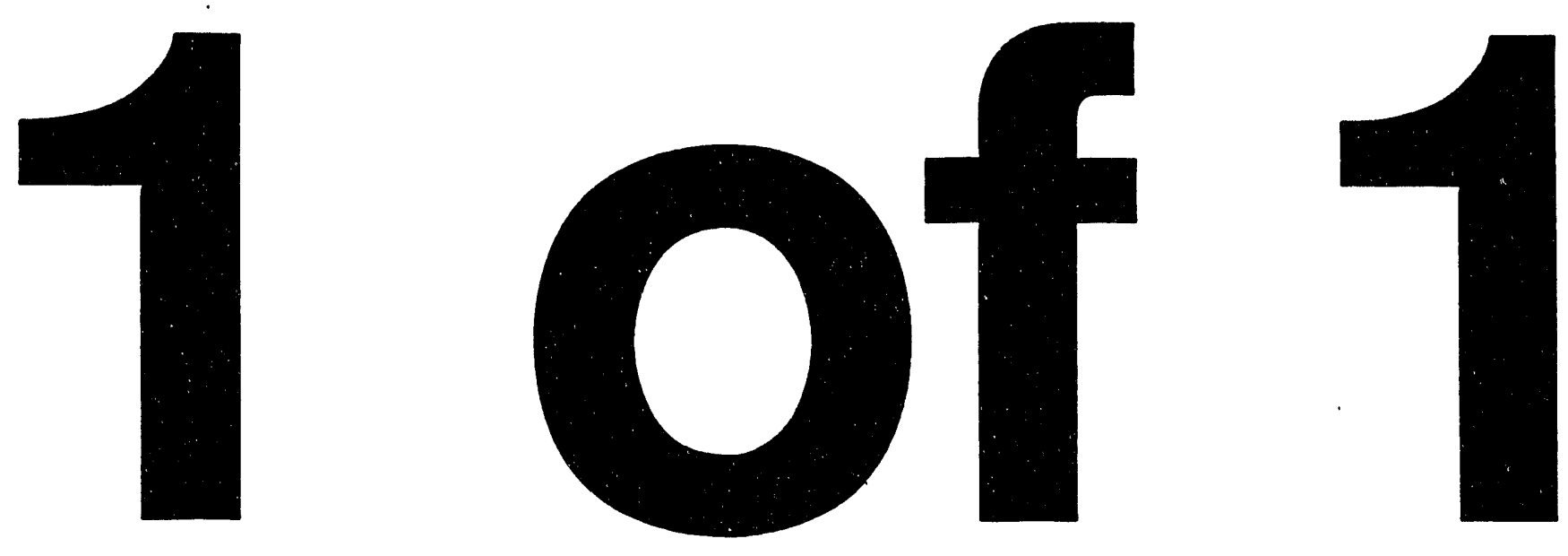


\section{"24/36/48" Cathode Strip Chamber Layout for SSC GEM Detector Muon Subsystem}

F. C. Belser, J. W. Clements, J. A. Horvath, S. M. Pratuch, T. J. Wenaus, D. M. Wright, C. R. Wuest, F. Nimblett, J. Paradiso, P. Sebelius, F. E. Taylor, J. Antebi, M. S. Zarghamee, M. Marx, C. V. Johnson, G. Mitselmakher, A. O. Steger

December 15, 1993

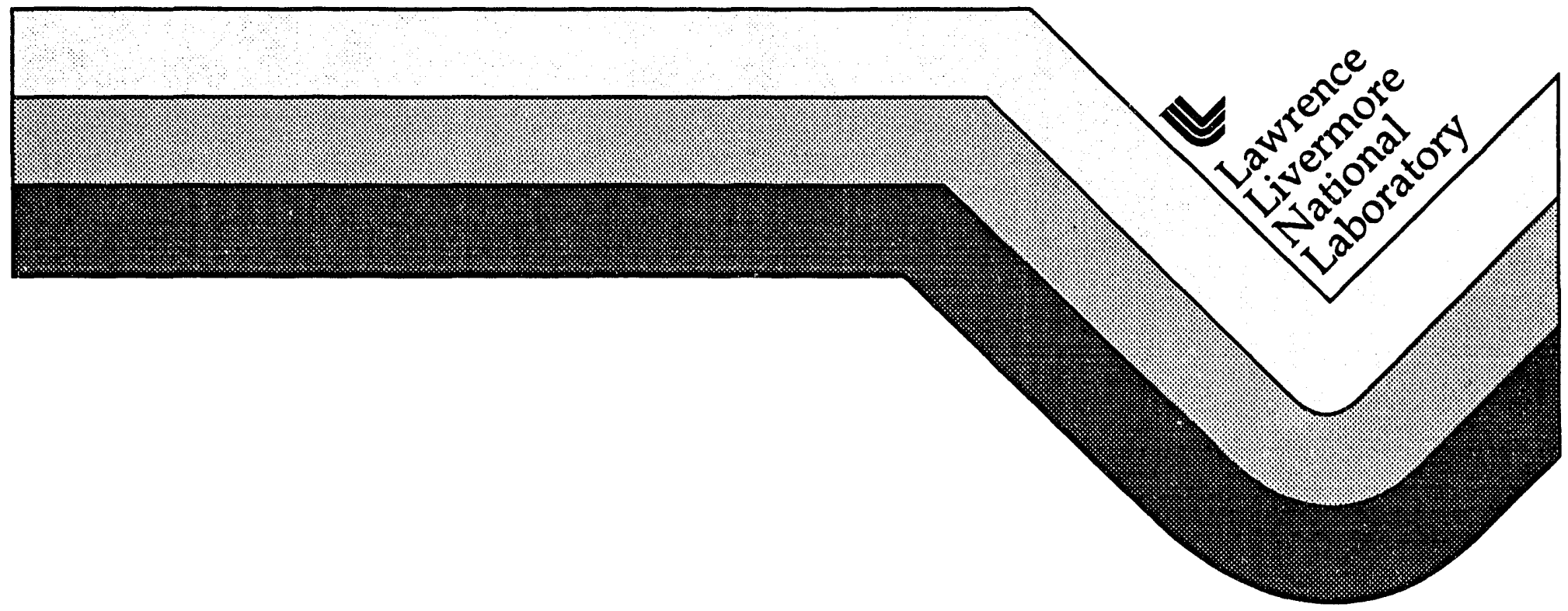




\section{DISCLAIMER}

This document was prepared as an account of work sponsored by an agency of the United States Government. Neither the United States Government nor the University of California nor any of their employees, makes any warranty, express or implied, or assumes any legal liability or responsibility for the accuracy: completeness, or usefulness of any information, apparatus, product, or process disclosed, or represents that its use would not infriage privately owned rights. Reference herein to any specific commercial products, process, or service by trade name, trademark, manufacturer, or otherwise, does net necessarily constitute or imply its endorsemeat, recommendation, or favoring by the United States Government or the University of Califormia. The views and opiaions of authors expressed herein do not necessarily state or reflect those of the United States Government or the University of California, and shall not be used for advertising or product endorsement purposes. 
GEM TN-93-518

\title{
“24/36/48" Cathode Strip Chamber Layout for SSC GEM Detector Muon Subsystem
}

F.C. Belser,

J.W. Clements, J.A. Horvath, S.M. Pratuch, T.J. Wenaus, D.M. Wright, C.R. Wuest

Lawrence Livermore National Laboratory, Livermore, CA

F. Nimblett, J. Paradiso, P. Sebelius

Charles Stark Draper Laboratories, Cambridge, MA

F.E. Taylor

Massachusetts Institute of Technology, Cambridge, MA

J. Antebi, M.S. Zarghamee

Simpson Gumpertz \& Heger Inc., Arlington, MA

M. Marx

State University of New York, Stony Brook, NY

C.V. Johnson, G. Mitselmakher, A.O. Steger

Superconducting Super Collider Laboratory, Dallas, TX

December 15, 1993

\begin{abstract}
The "48/48/48" $\phi$-segmentation design for the Cathode Strip Chambers in the GEM Detector produces a number of coverage "gaps" in $\phi$ and $\theta$. A revised " $24 / 36 / 48$ " $\phi$ segmentation layout provides increased geometric coverage and a significant reduction in the number of chambers in the detector. This will increase physics performance while reducing the labor costs associated with building and installing chambers in the GEM Detector. This paper documents the physical layout of the proposed change to the baseline chamber arrangement.
\end{abstract}




\section{Introduction}

The "48/48/48" $\phi$-segmentation for the Cathode Strip Chambers (CSC's), described in the GEM Technical Design Report ${ }^{1}$ (TDR), produces a number of coverage "gaps" in $\phi$ and $\theta$. The coverage gaps in the muon detector are caused mainly by physical separation between the ends of chambers (to accommodate cathode electronics and projective alignment) in the barrel assembly and between the barrel and endcap assemblies at the $\theta \approx 30^{\circ}$ interface.

\section{TDR Baseline Chamber Arrangement}

The so-called " $48 / 48 / 48$ " chamber arrangement in the TDR Baseline Design has 48 CSC's in the $\phi$-coordinate direction in each of the three superlayers for both the barrel and endcap assemblies. Also, the chambers are arranged in an "alternating-overlap" configuration in that direction.

In the barrel assembly Z-coordinate direction, there are two chambers positioned end-toend in Superlayer \#1 (inner), with four each in Superlayers \#2 (middle) and \#3 (outer). Cathode electronics mounted on the end of each chamber along with projective lines-of-site between chambers produce coverage gaps at these locations. Eight different size chamber designs are required for a barrel assembly.

Chambers in the endcap assembly superlayers are positioned with the long dimension aligned in the R-coordinate direction instead of the Z-coordinate direction as with the barrel chambers. Two chambers overlap radially in each of the three superlayers. Along with the alternating-overlap in the $\phi$-coordinate direction, complete coverage is achieved except at the $\theta \approx 30^{\circ}$ interface with the barrel assembly. Six different size chamber designs are required for an endcap assembly.

Further details can be found in section 4 of Reference 1.

\section{“24/36/48" Chamber Arrangement}

The primary difference with the TDR Baseline Design is the number and arrangement of chambers in the $\phi$ - and $\theta$-coordinate directions for the barrel assembly. In addition, a "tiled-overlap" configuration has been adopted which simplifies the chamber interface with the support structure. The number of chambers in the endcap assembly superlayers has also been changed to reflect the new arrangement in the barrel assembly. However, the alternating-overlap configuration has been maintained there.

Figure 1 depicts a cutaway view of a muon detector assembly using the proposed chamber arrangement. The CSC's for both the barrel and endcap regions are supported by a monolithic support structure instead of separate barrel and endcap structures as with the TDR Baseline Design. Alignment is to be implemented within a repeated $30^{\circ}$ sector as shown in Figure 2. The overall chamber arrangement (without support structure) for one sector and the naming convention used for the endcap chambers is illustrated in Figure 3.

The support structure shown in Figure 4 is a modification of the MIC2 monolithic design proposed by Simpson Gumpertz and $\mathrm{Heger}^{2}$ as a replacement for the TDR Baseline Design. A 4-point "partial" kinematic mounting design 3 (not shown) will be used to 


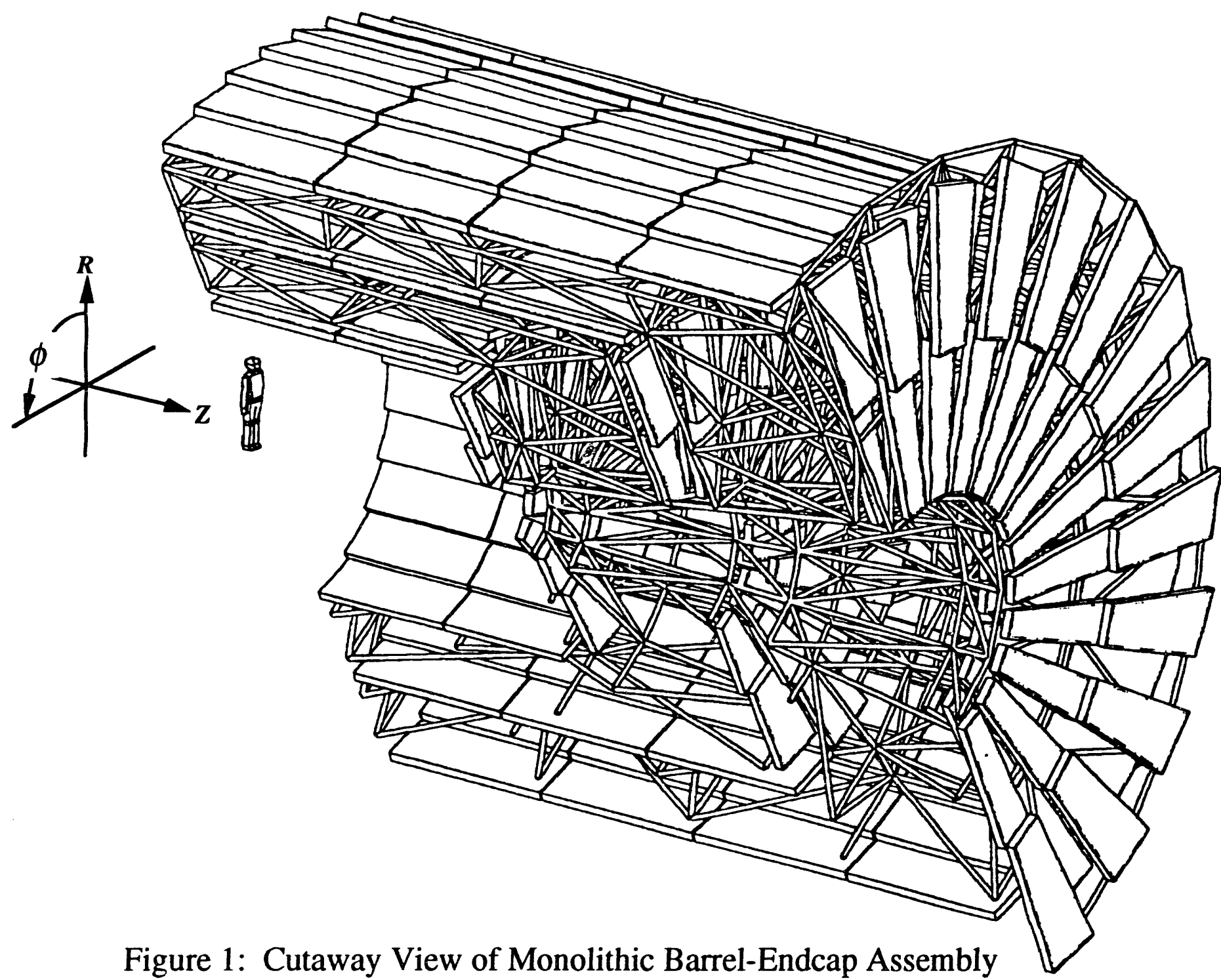

亩 


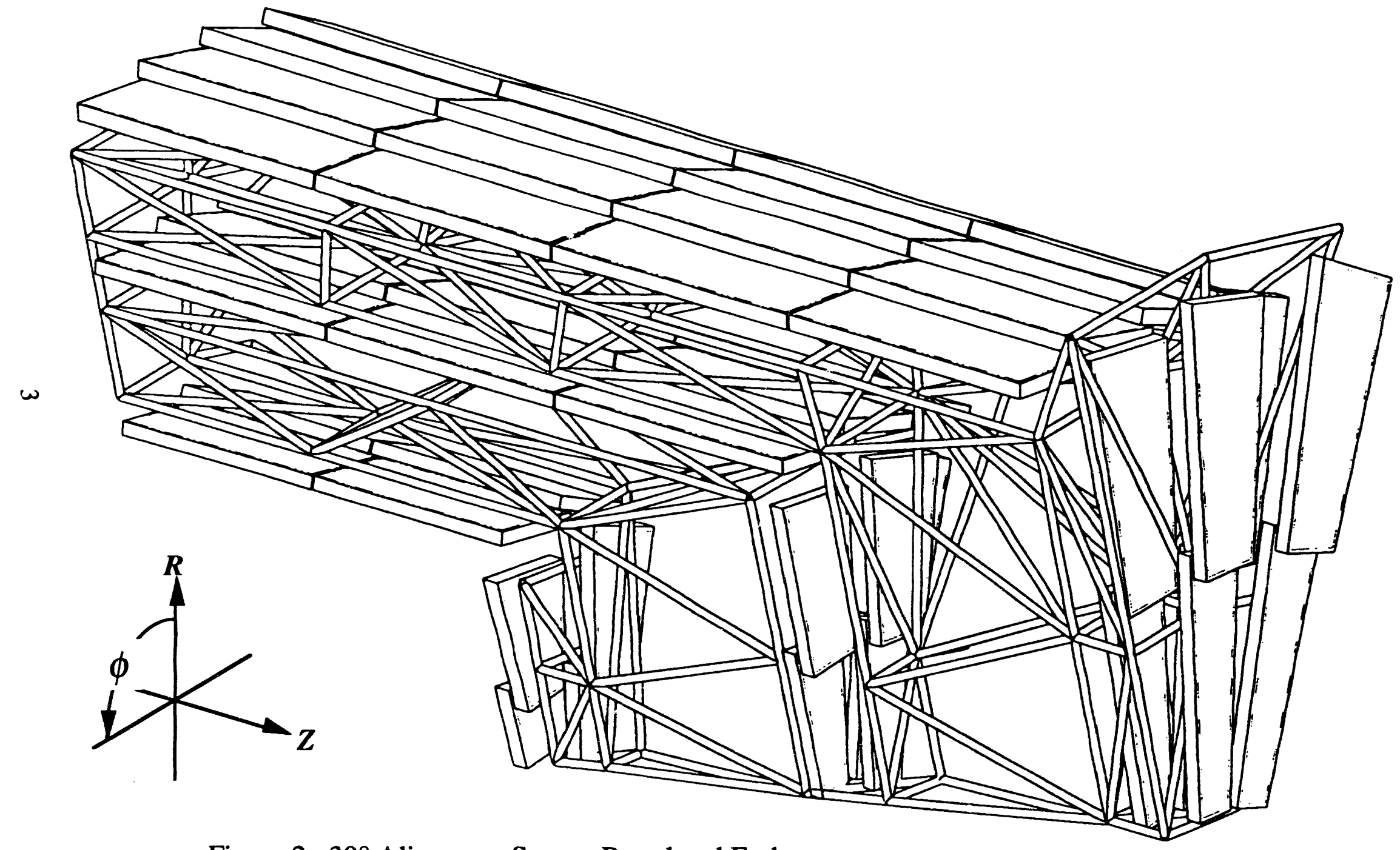

Figure 2: $30^{\circ}$ Alignment Sector, Barrel and Endcap 


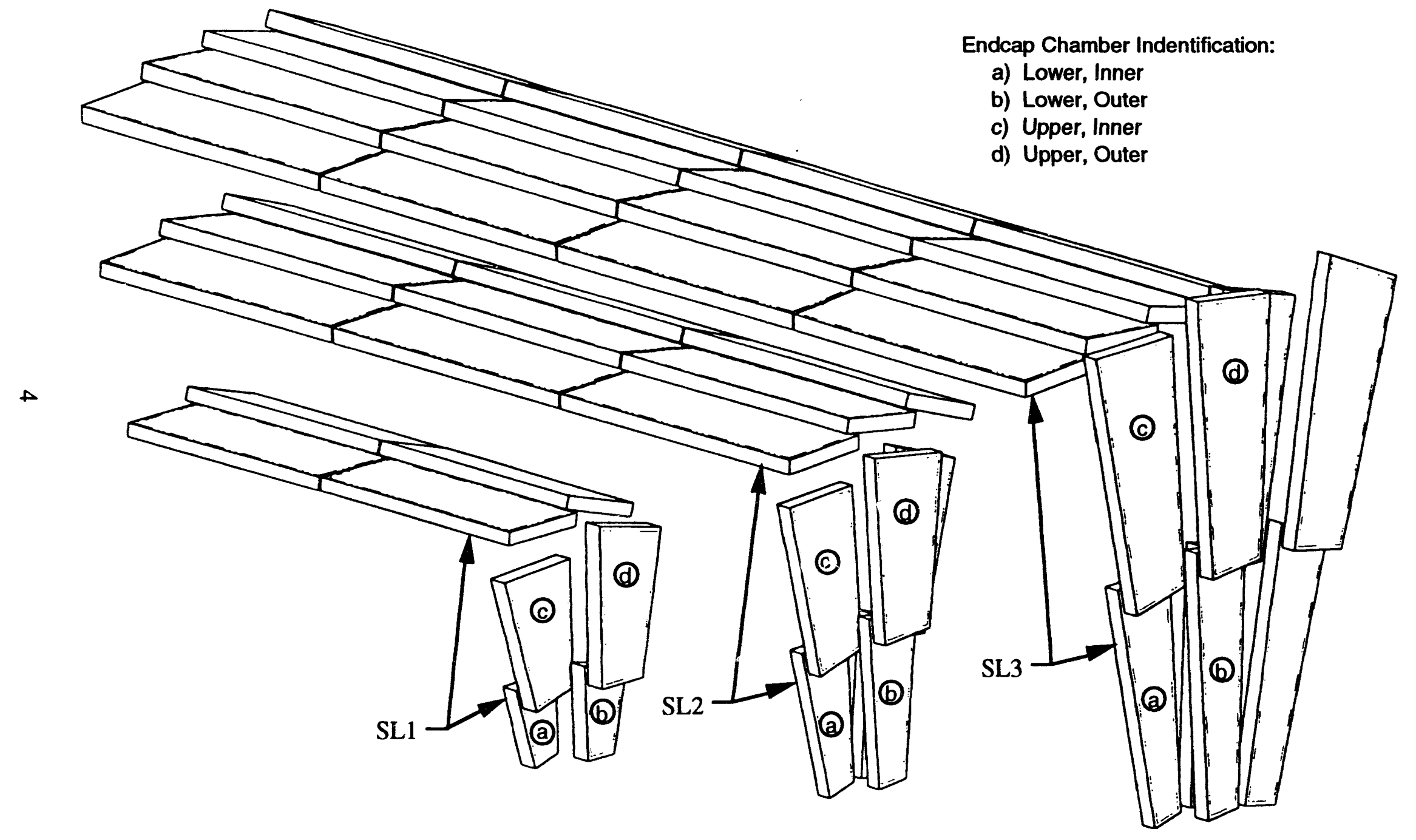

Figure 3: Cathode Strip Chamber Layout (30 Alignment Sector) 


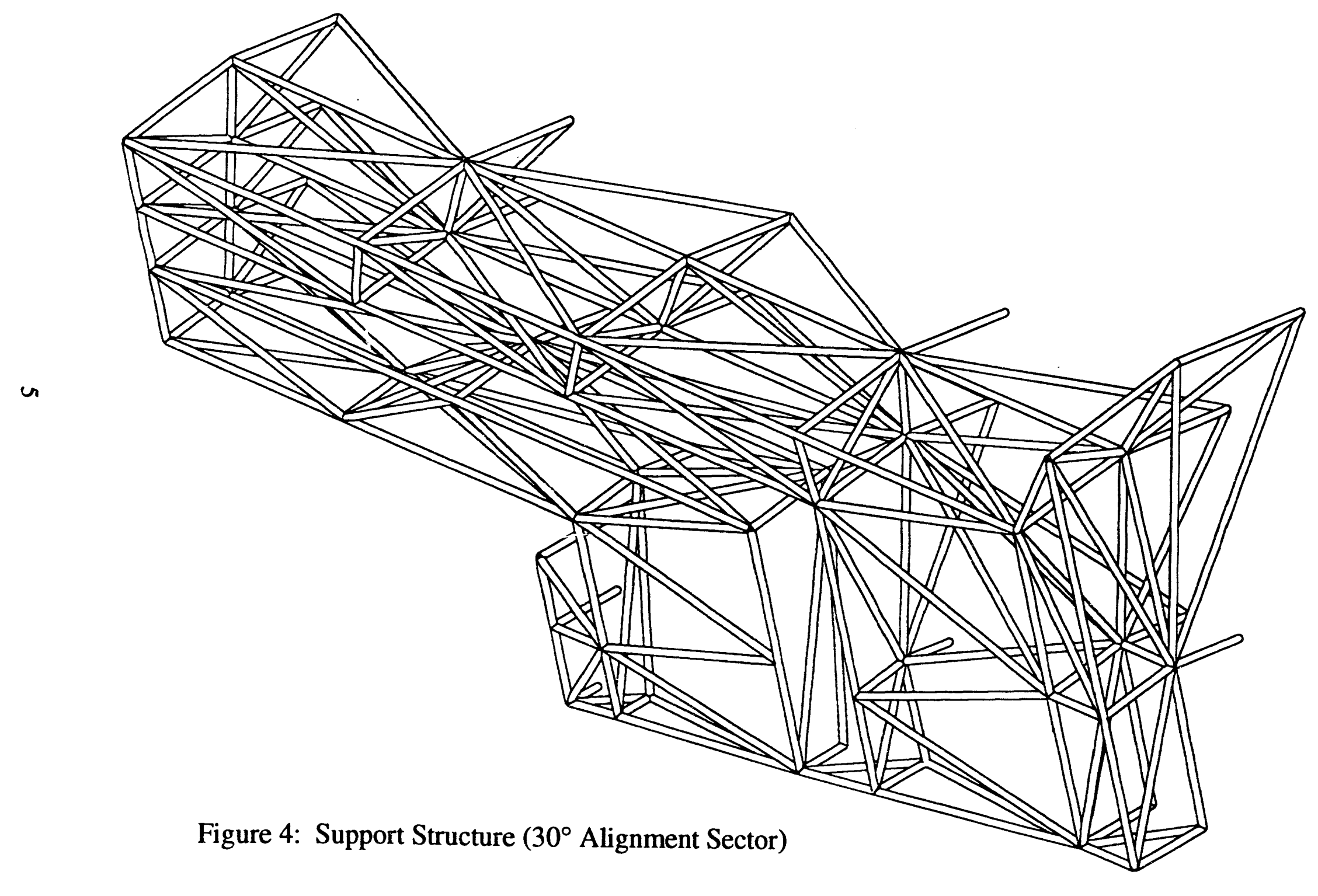

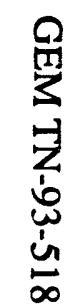


support each chamber in the support structure. The "tiled" chamber arrangement in the barrel region also simplifies the chamber supports by replacing two different geometric support designs (required for the alternating-overlap configuration in the TDR Baseline Design) with a single, repeated design for each superlayer.

The monolithic assembly concept produces a lighter structure, when truss element dimensions are optimized for the imposed loading, and improves access to the interior of the assembly. For the first iteration however, 4 inch diameter truss elements were used throughout. Larger members may prove necessary to meet other performance criteria and as future optimization of diamt ter and wall thickness of members are performed to reduce total mass.

The barrel region chamber parameters, sizes, and locations within a sector are listed in Tables 1, 2, and 3 respectively. Note that only three different size chamber designs are required.

\begin{tabular}{|c|c|c|c|}
\hline \multirow[t]{2}{*}{ Barrel Chamber Parameters - } & \multicolumn{3}{|c|}{ "24/36/48" Tiled Layout } \\
\hline & $\begin{array}{c}\text { SL1 } \\
\text { (inner) }\end{array}$ & $\begin{array}{c}\text { SL2 } \\
\text { (middle) }\end{array}$ & $\begin{array}{c}\text { SL3 } \\
\text { (outer) }\end{array}$ \\
\hline Chamber segmentation in $\phi$ & 24 & 36 & 48 \\
\hline Chambers per alignment sector in $\phi$ & 2 & 3 & 4 \\
\hline Chamber segmentation in $z$ & 2 & 3 & 4 \\
\hline Detection layers per chamber & 6 & 6 & 6 \\
\hline Anode-cathode gap, $\mathrm{m}$ & 0.00254 & 0.004 & 0.005 \\
\hline Lorentz angle, degrees & 12.0 & 12.0 & 12.0 \\
\hline $\begin{array}{l}\text { Inner radius: } 3.9 \mathrm{~m} \text { (minimum limit) } \\
\text { Outer radius: } 8.9 \mathrm{~m} \text { (maximum limit) } \\
\text { Lever Arm: } 4.569 \mathrm{~m} \text { (center of } \mathrm{SL} \text { to cen }\end{array}$ & ter of SL3) & & \\
\hline
\end{tabular}

Table 1

\begin{tabular}{|c|c|c|c|}
\hline \multicolumn{4}{|c|}{ Barrel Chamber Dimensions } \\
\hline Superlayer & $\begin{array}{c}\text { Length[a,b], } \\
\mathbf{m}\end{array}$ & $\begin{array}{c}\text { Width[b], } \\
\mathbf{m}\end{array}$ & $\begin{array}{c}\text { Thickness, } \\
\mathbf{m}\end{array}$ \\
\hline SL1 & $2.950(2.842)$ & $1.275(1.167)$ & 0.17048 \\
\hline SL2 & $3.560(3.452)$ & $1.330(1.222)$ & 0.188 \\
\hline SL3 & $3.680(3.572)$ & $1.350(1.242)$ & 0.200 \\
\hline
\end{tabular}

Notes: a) Gap between ends of chambers $=0.025 \mathrm{~m}$

b) "Active" region in parentheses; $0.054 \mathrm{~m}$ inactive region around perimeter.

Table 2 


\begin{tabular}{|c|c|c|c|c|}
\hline \multicolumn{5}{|c|}{ Barrel Chamber Locations (Center of Chamber) } \\
\hline Superlayer & $\boldsymbol{R}, \mathbf{m}$ & $\phi[\mathbf{a}]$, degrees & & ], $\mathbf{m}$ \\
\hline SL 1 & 4.069 & $+7.50 \quad(-7.50)$ & $\begin{array}{l}\# 1 \\
\# 2\end{array}$ & $\begin{array}{l}1.975 \\
4.950\end{array}$ \\
\hline SL2 & 6.400 & $+10.00 \quad(0.00)(-10.00)$ & $\begin{array}{l}\# 1 \\
\# 2 \\
\# 3\end{array}$ & $\begin{array}{l}2.355 \\
5.940 \\
9.525\end{array}$ \\
\hline SL3 & 8.638 & $+11.25(+3.75)(-3.75) \quad(-11.25)$ & $\begin{array}{l}\# 1 \\
\# 2 \\
\# 3 \\
\# 4\end{array}$ & $\begin{array}{r}2.590 \\
6.295 \\
10.000 \\
13.705\end{array}$ \\
\hline
\end{tabular}

Notes: a) Repeated chambers within a $30^{\circ}$ alignment sector are listed in parentheses.

b) All chambers listed within a particular superlayer have the same $\boldsymbol{R}$ and $\phi$.

Table 3

A side view ( $R-Z$ plane) detailing the barrel chambers in the monolithic assembly is shown in Figure 5. In order to increase detector coverage by reducing the gap between barrel chamber ends to $25 \mathrm{~mm}$, the cathode electronics must be moved from the chamber ends to some other location, i.e. the chamber face. Coverage was further increased by reducing the "inactive" width around the perimeter of each barrel chamber ${ }^{4}$ to $54 \mathrm{~mm}$, particularly important at the chamber ends. End views $(R-\phi$ plane) of the barrel chambers from vantage points in each of the three endcap superlayers are shown in Figures 6, 7, and 8.

The endcap region chamber parameters, sizes, and locations within a sector are listed in Tables 4,5 , and 6 respectively.

\begin{tabular}{|c|c|c|c|}
\hline \multicolumn{4}{|c|}{$\begin{array}{l}\text { Endcap Chamber Parameters - } \\
\text { "24/36/48" Alternating-Overlap Layout }\end{array}$} \\
\hline & $\begin{array}{c}\text { SL 1 } \\
\text { (inner) }\end{array}$ & $\begin{array}{c}\text { SL2 } \\
\text { (middle) }\end{array}$ & $\begin{array}{c}\text { SL3 } \\
\text { (outer) }\end{array}$ \\
\hline Chamber segmentation in $\phi$ & 24 & 36 & 48 \\
\hline Chambers per alignment sector in $\phi$ & $T B D$ & $T B D$ & $T B D$ \\
\hline Chamber segmentation in $R$ & 2 & 2 & 2 \\
\hline Detection layers per chamber & 8 & 6 & 6 \\
\hline Anode-cathode gap, m & 0.00254 & 0.004 & 0.005 \\
\hline Chamber thickness, $\mathrm{m}$ & 0.22064 & 0.188 & 0.200 \\
\hline Lorentz angle, degrees[a] & 12.0 & 12.0 & 12.0 \\
\hline
\end{tabular}

Note: Implemented within the chamber by rotating the anode wires in the $R-\phi$ plane.

Table 4 


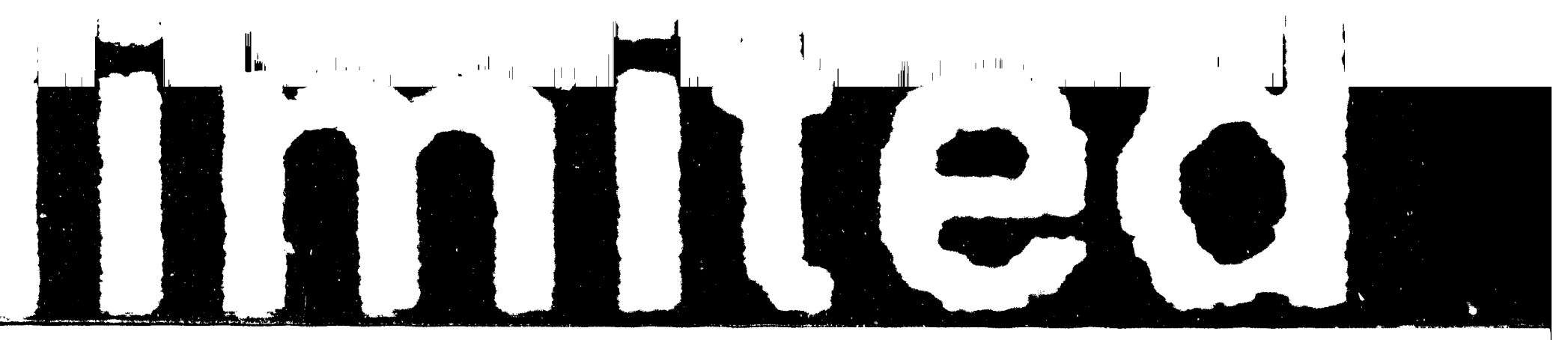

GEM TN-93-518

\begin{tabular}{|c|c|c|c|c|c|}
\hline \multicolumn{6}{|c|}{ Endcap Chamber Dimensions } \\
\hline \multicolumn{2}{|c|}{$\begin{array}{c}\text { Superlayer } \\
\text { Location }\end{array}$} & $\begin{array}{c}\text { Width at } \\
\text { Top }[\mathbf{a}], \mathbf{m} \\
\end{array}$ & $\begin{array}{c}\text { Width at } \\
\text { Bottom }[\mathrm{a}], \mathrm{m}\end{array}$ & $\begin{array}{c}\text { Length[a], } \\
\text { m } \\
\end{array}$ & $\begin{array}{c}\text { Thickness, } \\
\text { m }\end{array}$ \\
\hline \multirow[t]{4}{*}{$\overline{\text { SL1 }}$} & Lower, Inner & $0.7458(0.6378)$ & $0.4500(0.3420)$ & $1.0553(0.9461)$ & 0.22064 \\
\hline & Lower, Outer & $0.7954(0.6874)$ & $0.4750(0.3670)$ & $1.1400(1.0308)$ & 0.22064 \\
\hline & Upper, Inner & $1.2305(1.1225)$ & $0.7000(0.5920)$ & $1.7682(1.6590)$ & 0.22064 \\
\hline & Upper, Outer & $1.1658(1.0578)$ & $0.7400(0.6320)$ & $1.9662(1.8570)$ & 0.22064 \\
\hline \multirow[t]{4}{*}{ SL2 } & Lower, Inner & $0.8765(0.7685)$ & $0.4750(0.3670)$ & $19570(18478)$ & \\
\hline & Lower, Outer & $0.9268(0.8188)$ & $0.5000(0.3920)$ & $2.1267(2.0175)$ & 0.188 \\
\hline & Upper, Inner & $1.2055(1.0975)$ & $0.8000(0.6920)$ & $2.2725(2.1633)$ & 0.188 \\
\hline & Upper, Outer & $1.3037(1.1957)$ & $0.8500(0.7420)$ & $2.3218(2.2126)$ & 0.188 \\
\hline \multirow{4}{*}{ SL3 } & Lower Inner & $09720(08640)$ & $05000(03020$ & & \\
\hline & Lower, Outer & $0.9358(0.8278)$ & $0.5800(0.4720)$ & $3.3767(3.2675)$ & 0.200 \\
\hline & Upper, Inner & $1.4351(1.3271)$ & $0.9150(0.8070)$ & $3.4286(3.3194)$ & 0.200 \\
\hline & Upper, Outer & $1.4107(1.3027)$ & $0.9000(0.7920)$ & $3.5012(3.3920)$ & 0.200 \\
\hline
\end{tabular}

Note: "Active" region in parentheses; $0.054 \mathrm{~m}$ inactive region around perimeter.

Table 5

\begin{tabular}{|c|c|c|c|c|}
\hline \multicolumn{5}{|c|}{ Endcap Chamber Locations (Center of Chamber) } \\
\hline \multicolumn{2}{|c|}{ Superlayer } & $\boldsymbol{R}, \mathbf{m}$ & $\phi[\mathbf{a}]$, degrees & $\mathbf{Z}, \mathbf{~ m}$ \\
\hline \multirow{3}{*}{ SL1 } & Lower, Inner & 1.525 & +11.00 & 6.11032 \\
\cline { 2 - 5 } & Lower, Outer & 1.676 & -4.00 & 6.75032 \\
\cline { 2 - 5 } & Upper, Inner & 2.810 & +11.00 & 6.38032 \\
\cline { 2 - 5 } & Upper, Outer & 3.100 & -4.00 & 7.02032 \\
\hline & & & & \\
\hline SL 2 & Lower, Inner & 2.772 & $+10.00(-10.00)$ & 10.850 \\
\cline { 2 - 5 } & Lower, Outer & 2.950 & 0.00 & 11.420 \\
\cline { 2 - 5 } & Upper, Inner & 4.725 & $+10.00(-10.00)$ & 11.080 \\
\cline { 2 - 5 } & Upper, Outer & 5.000 & 0.00 & 11.650 \\
\hline & & & & 16.050 \\
\hline \multirow{3}{*}{ SL3 } & Lower, Inner & 4.253 & $+8.50(-6.50)$ & 16.650 \\
\cline { 2 - 5 } & Lower, Outer & 4.440 & $+1.00(-14.00)$ & 16.300 \\
\cline { 2 - 5 } & Upper, Inner & 7.400 & $+8.50(-6.50)$ & 16.900 \\
\cline { 2 - 5 } & Upper, Outer & 7.715 & $+1.00(-14.00)$ & \\
\hline
\end{tabular}

Note: Repeated chambers within a $30^{\circ}$ sector are listed in parentheses.

Table 6 


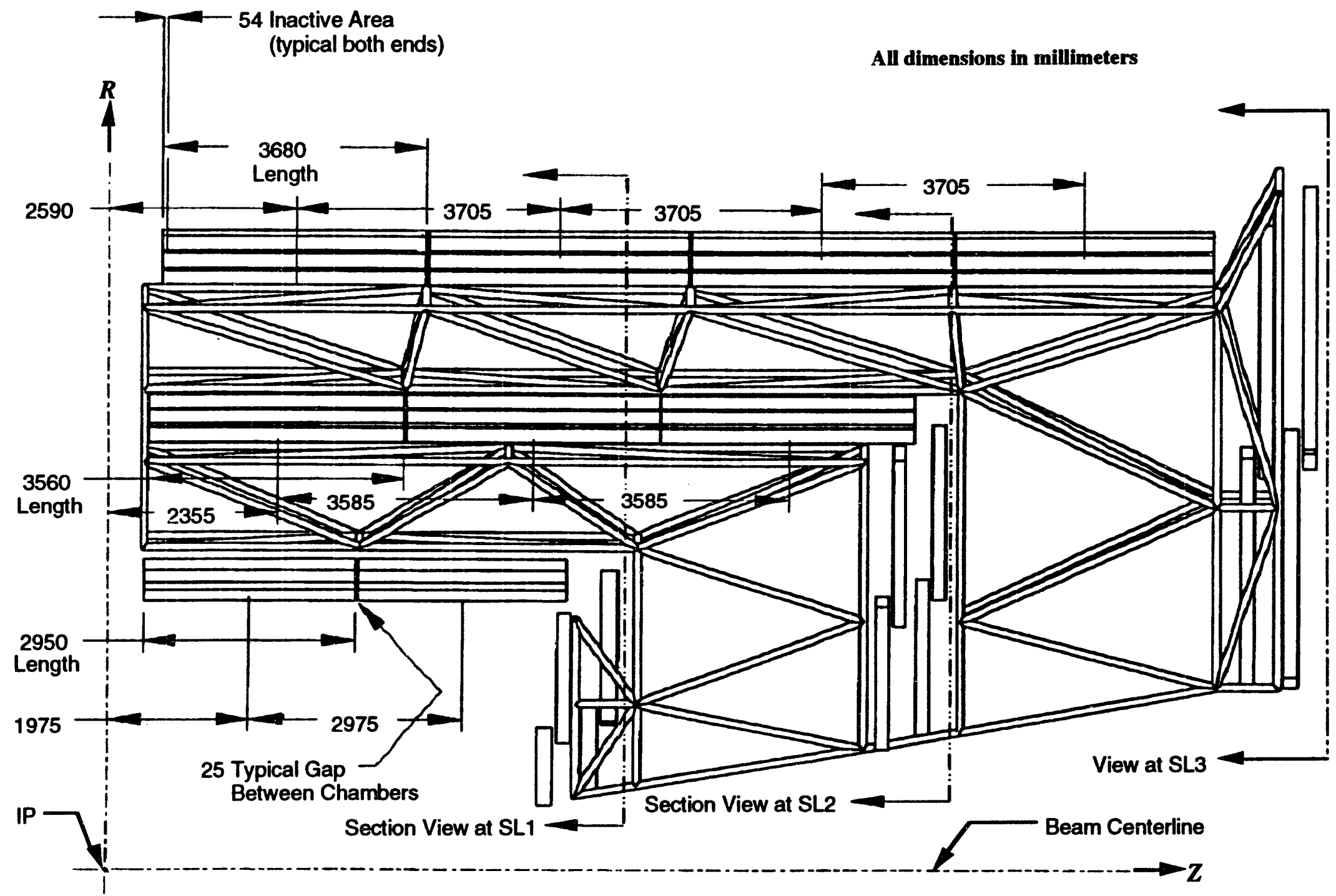

Figure 5: Side View of Barrel-Endcap Assembly (Barrel Chamber Locations \& Lengths) 
GEM TN-93-518

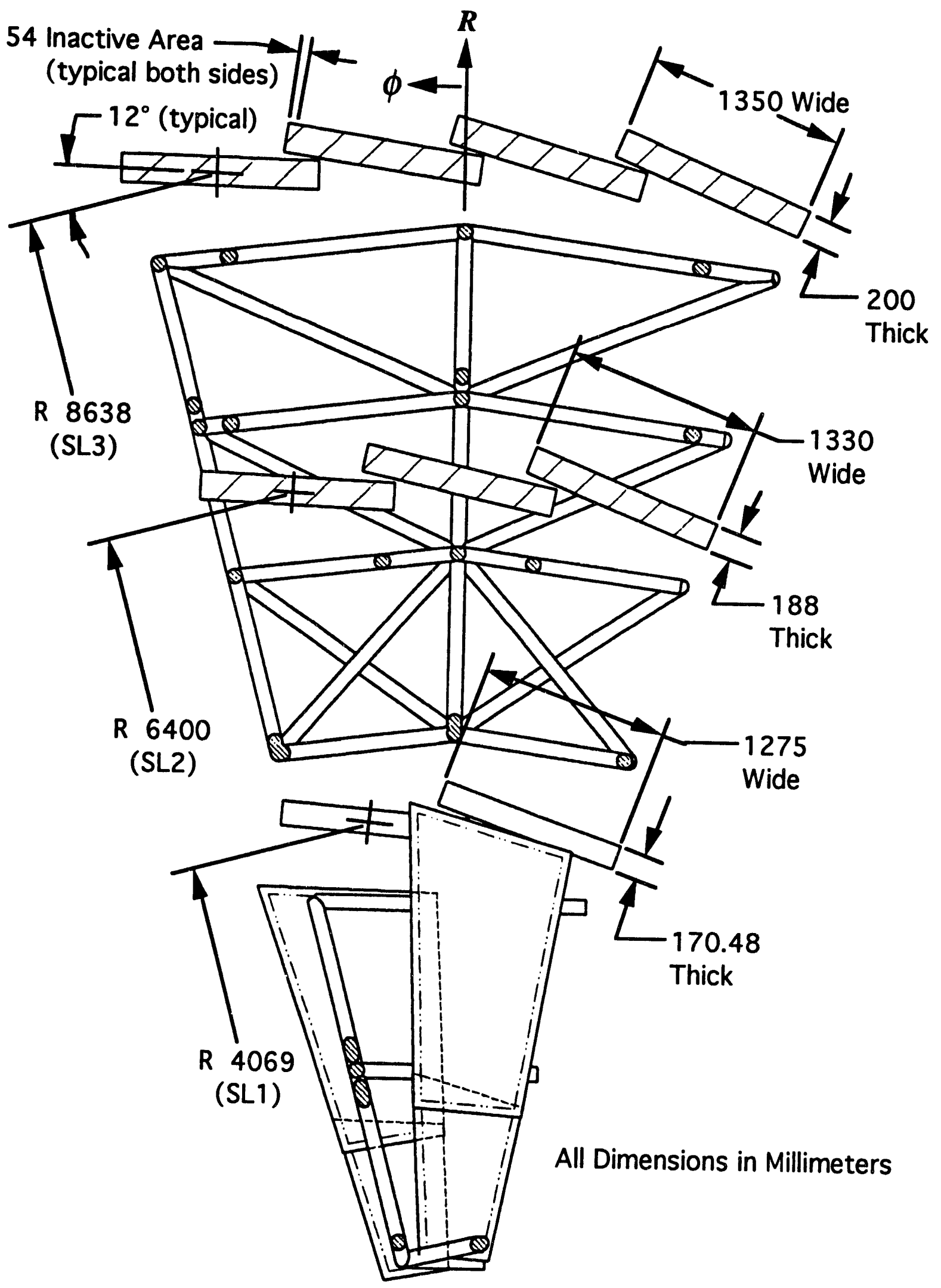

Figure 6: View from Endcap at SL1 (30 ${ }^{\circ}$ Alignment Sector) 


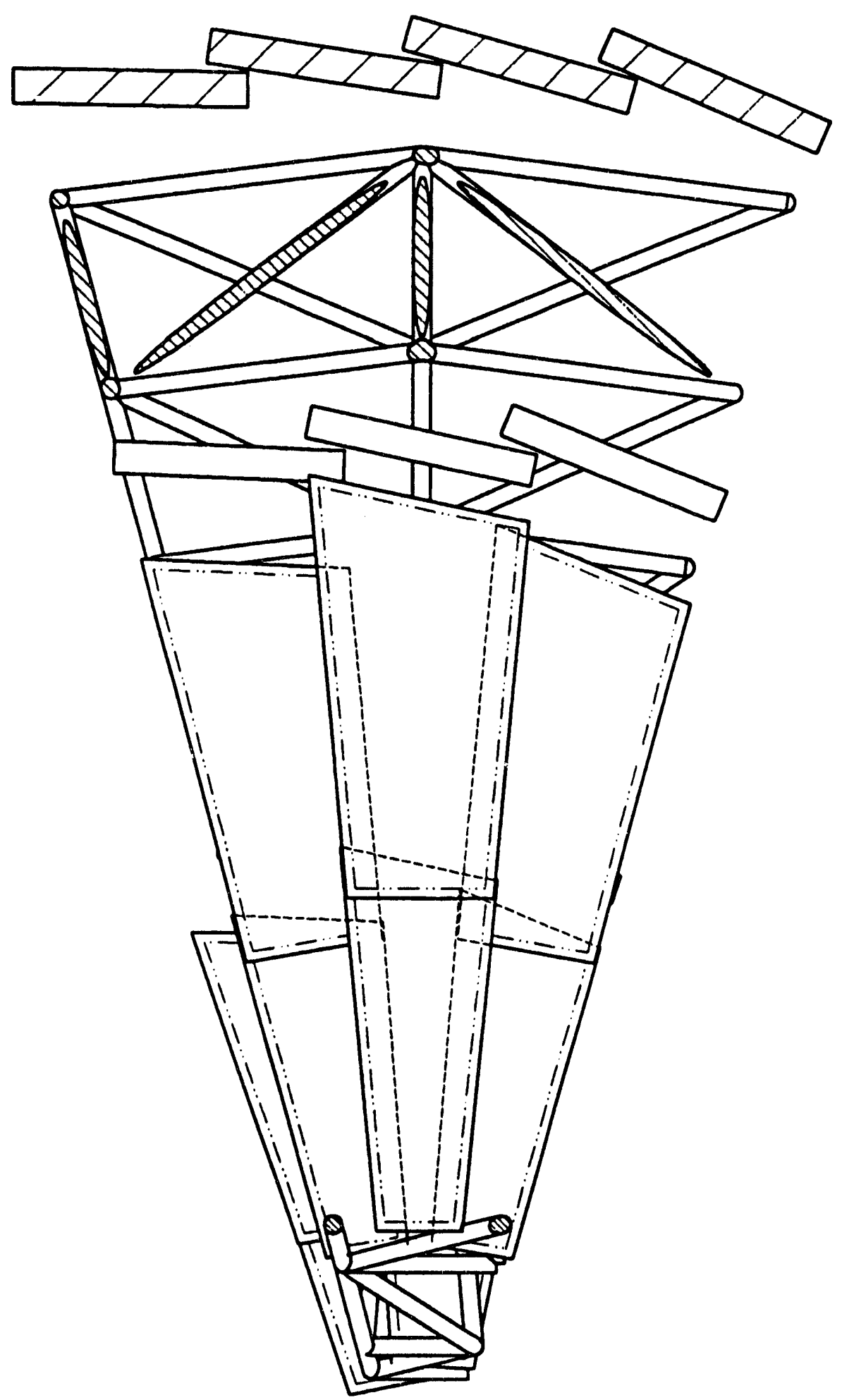

Figure 7: View from Endcap at SL2 (30 Alignment Sector) 
GEM TN-93-518

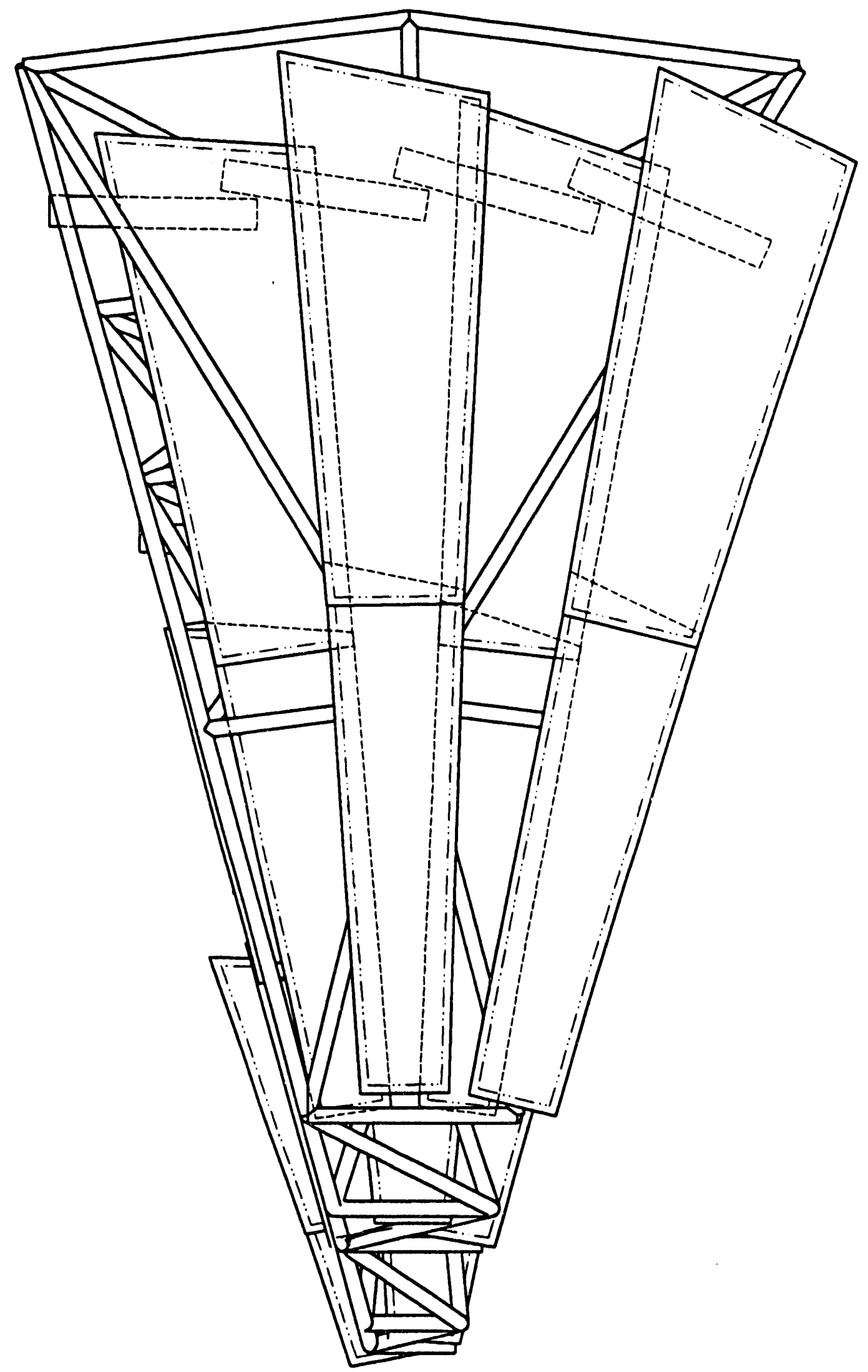

Figure 8: View from Endcap at SL3 (30 Alignment Sector) 
Figure 9 shows a typical trapezoidal-shaped endcap chamber (refer to Table 5). Although twelve different endcap chamber sizes are required in this arrangement, it should be possible to reduce this to six. A single, optimized design should be developed to replace the lower inner and lower outer chambers and similarly another design to replace the upper inner and upper outer chambers in each superlayer.

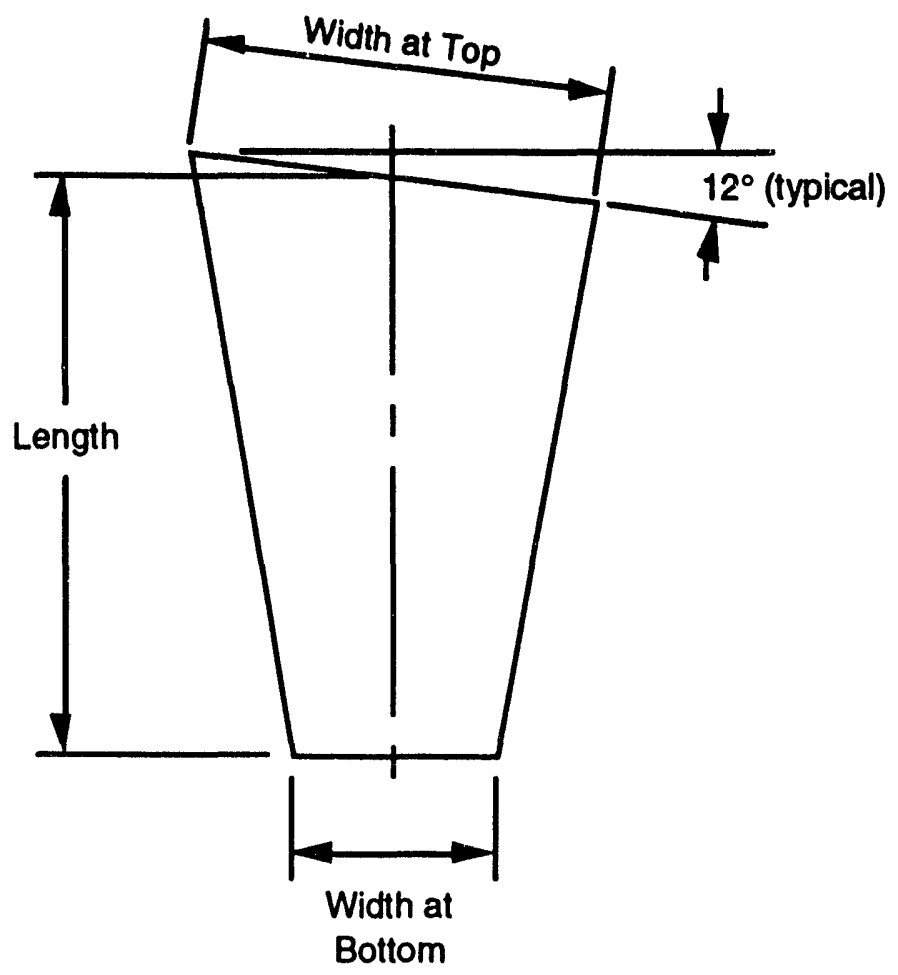

Figure 9: Typical Endcap Chamber

The forward field shaper (FFS) interface with the endcap region is illustrated in Figure 10. Also shown is the "clear zone" at the barrel-endcap interface reserved for alignment linesof-site. It is assumed that the inner and outer superlayer interfaces can accommodate an alignment system while preserving chamber overlap at the interface.

The minimum overlap of chamber "active" regions is listed in Table 7. This needs further optimization during the next iteration of chamber arrangement and sizes. Preferably, a single value should be selected.

\begin{tabular}{|c|c|c|}
\hline \multicolumn{3}{|c|}{$\begin{array}{c}\text { Minimum Overlap of "Active" } \\
\text { Chamber Regions }\end{array}$} \\
\hline $\begin{array}{c}\text { Superlayer } \\
\text { Location }\end{array}$ & Barrel, mm & Endcap, mm \\
\hline SL1 & 34.8 & 69 \\
\hline SL2 & 36.6 & 67 \\
\hline SL3 & 41.0 & 72 \\
\hline
\end{tabular}

Table 7 


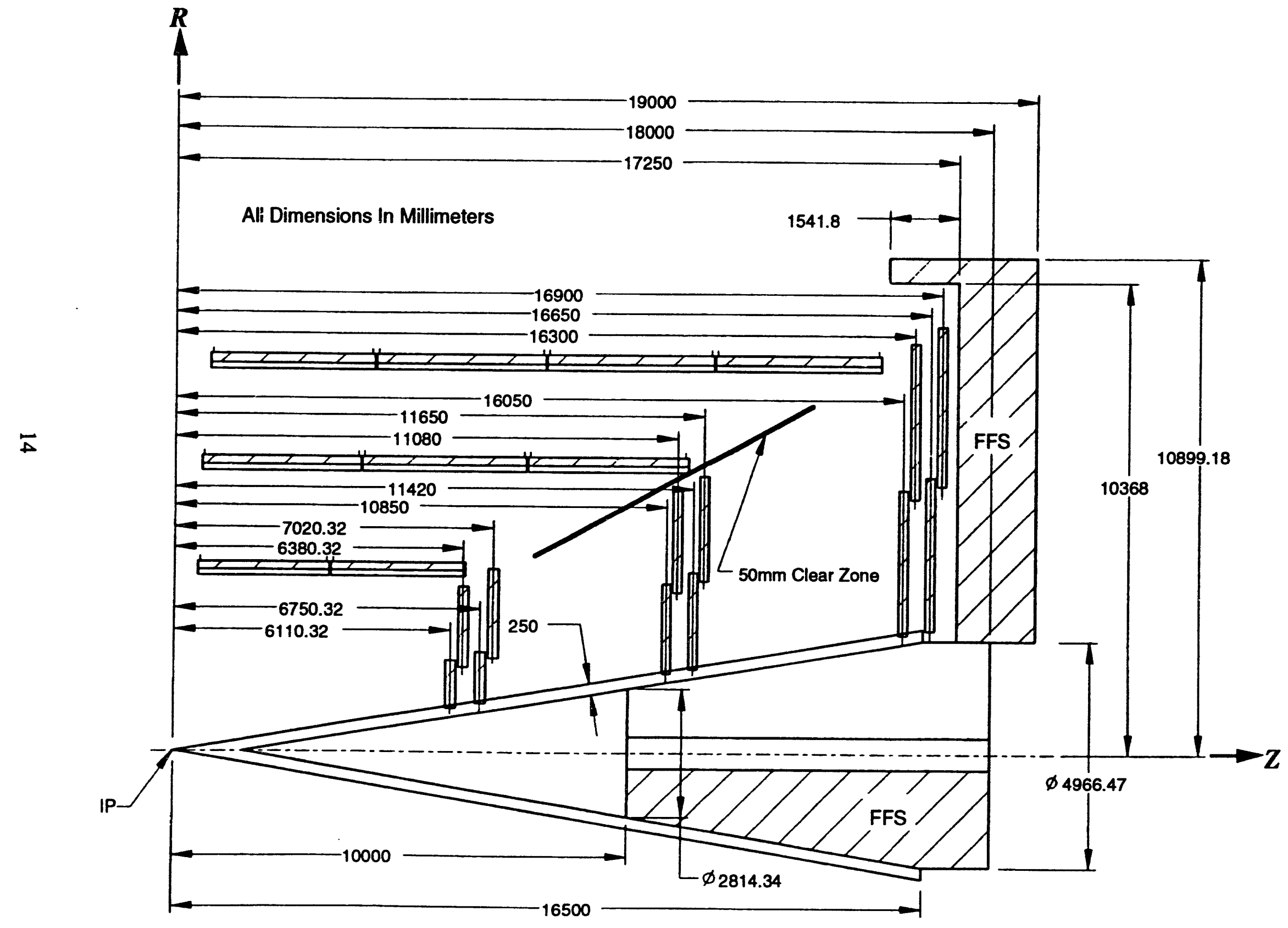

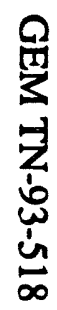

Figure 10: Location of Endcap Chambers and Forward Field Shaper (FFS)

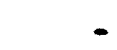




\section{Comparison with the TDR Baseline Design}

Material costs and assembly labor (barrel chambers only) for various chamber arrangements is compiled in Table 8. The "24/36/48" proposal is highlighted and the "48/48/48" TDR Baseline design (last row) is also included for comparison.

\begin{tabular}{|c|c|c|c|c|c|}
\hline \multicolumn{6}{|c|}{ Summary Cost Estimates[a]: Barrel Chambers } \\
\hline \multicolumn{2}{|c|}{ Chamber Arrangement } & \multicolumn{2}{|c|}{3.7 m Inner Radius } & $3.9 \mathrm{~m}$ Inn & er Radius \\
\hline $\begin{array}{c}\text { SL1/SL2/SL3 } \\
\text { (Superlayer Totals) }\end{array}$ & $\begin{array}{c}\text { Total } \\
\text { Chambers }\end{array}$ & $\begin{array}{c}\text { Material } \\
\text { k\$ }\end{array}$ & $\begin{array}{c}\text { Labor } \\
\text { man-years }\end{array}$ & $\begin{array}{c}\text { Material } \\
\text { k\$ }\end{array}$ & $\begin{array}{c}\text { Labor } \\
\text { man-years }\end{array}$ \\
\hline $\begin{array}{c}32 / 32 / 32[6] \\
(128 / 192 / 256)\end{array}$ & 576 & $\$ 13,846$ & 56.16 & $\$ 13,910$ & 56.24 \\
\hline $\begin{array}{c}32 / 32 / 48 \\
(128 / 192 / 384)\end{array}$ & 704 & $\$ 14,340$ & 68.64 & $\$ 14,404$ & 68.74 \\
\hline 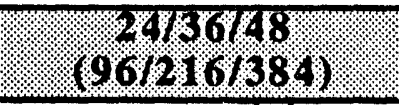 & 696. & $\$ 14,573$ & 67.82 & $\$ 60601$ & 68.00 \\
\hline $\begin{array}{c}48 / 48 / 48[c] \\
(192 / 384 / 384)\end{array}$ & 960 & & & $\$ 14,994$ & 148.09 \\
\hline
\end{tabular}

Notes: a) Provided by F. Nimblett and P. Sebelius (Charles Stark Draper Laboratory), 21 September 1993.

b) Requires extra-wide chambers for SL3.

c) TDR Baseline Design.

Table 8

There is very little difference in material costs among the various alternatives because of the "fixed" detector area to be covered. However, significant savings may be realized in assembly labor by using fewer, larger chambers compared to the TDR Baseline Design. This should also hold true for the endcap chambers, although an estimate is needed.

Ultimately, all the "3.7 m Inner Radius" options were eliminated because a smaller radius would likely create a very tight dimensional interface problem with the existing calorimeter design. Of the " $3.9 \mathrm{~m}$ Inner Radius" options, the " $32 / 32 / 32$ " arrangement was eliminated because it required a SL3 chamber design that exceeds current manufacturing size capability. Of the remaining two options, the costs and labor differences were negligible.

The "24/36/48" arrangement was selected because it is probably more compatible with proposed (axial-projective hybrid) revisions to the baseline alignment system. This chamber arrangement is not compatible with the projective alignment system defined in the TDR Baseline Design; there is not enough room for the lines-of-site between the ends of the chambers.

\section{Summary}

The proposed " $24 / 36 / 48$ " $\phi$-segmentation layout opens the possibility for increased coverage. Monte Carlo analysis is required to verify an expected increase in physics performance. In addition, the proposed revision to the TDR Baseline Design requires significantly fewer chambers in the detector assembly. Estimates indicate a significant reduction in the labor costs associated with building and installing chambers in the GEM 
Detector. However, interface issues with proposed revisions to the CSC alignment system must be resolved.

In fine-tuning the final chamber arrangement, the chamber alignment system must be an integral part of the chamber layout process. Furthermore, it may be possible to reduce chamber dimensions slightly by optimizing "active region" overlap from one chamber to the next. This may also lead to a reduction of $50 \%$ in the number of different endcap chamber designs. 


\section{References}

1. GEM TN-93-262, GEM Technical Design Report, April 30, 1993

2. GEM TN-93-519, Monolithic Integrated Concepts for Muon Subsystem Structures, June 8, 1993

3. GEM TN-93-510, Cathode Strip Chamber Interface with Support Structure for SSC GEM Detector Muon Subsystem, December 8, 1993

4. GEM TN-93-460, Comparison of Gap Frame Designs and Materials for Precision Cathode Strip Chambers, September 9, 1993 

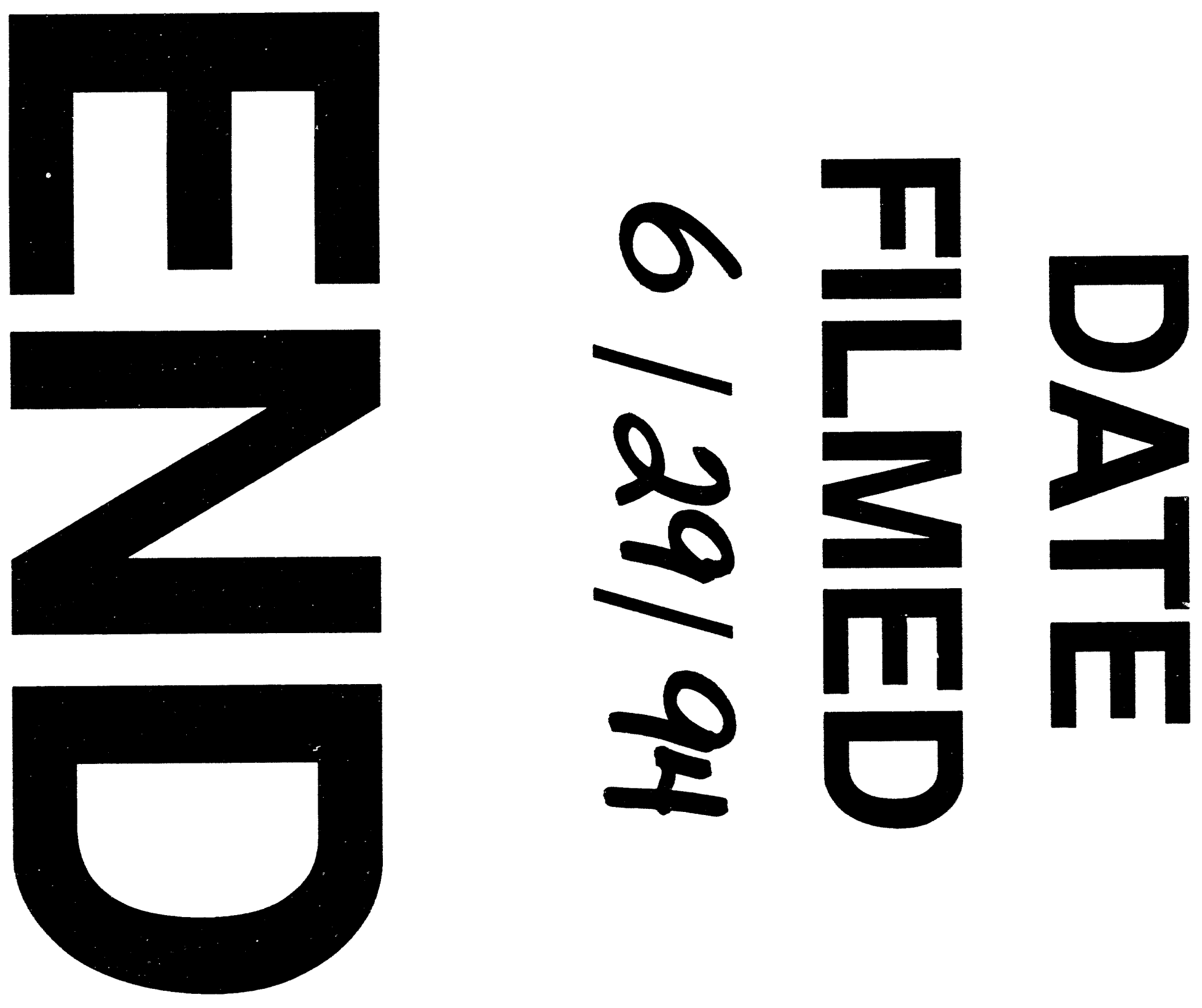
L 